\title{
HIV-1 Kills Renal Tubular Epithelial Cells In Vitro by Triggering an Apoptotic Pathway Involving Caspase Activation and Fas Upregulation
}

\author{
Pier Giulio Conaldi, ${ }^{\star}$ Luigi Biancone, ${ }^{\ddagger}$ Antonella Bottelli, ${ }^{\star \S}$ Alison Wade-Evans, \\ Mariarosaria Boccellino, ${ }^{\ddagger}$ Viviana Orlandi, ${ }^{*}$ Caterina Serra, ${ }^{* \star}$ Giovanni Camussi, ${ }^{\ddagger}$ and Antonio Toniolo* \\ *Division of Microbiology and ${ }^{\ddagger}$ Division of Nephrology, Department of Clinical and Biological Sciences, University of Insubria, Varese \\ 21100, Italy; ${ }^{\S}$ Institute of Forensic Medicine, University of Brescia, Brescia 25123, Italy; "Division of Retrovirology, National Institute for \\ Biological Standards and Control, South Mimms, Potters Bar, Herts, United Kingdom EN6 3QG; "IDepartment of Pathology, The Johns \\ Hopkins University School of Medicine, Baltimore, Maryland 21205; and **Institute of Microbiology and Virology, University of Sassari, \\ Sassari 07100, Italy
}

\begin{abstract}
HIV-infected patients suffer several renal syndromes, which can progress rapidly from renal insufficiency to end-stage renal disease. Histologically, HIV-induced nephropathy is characterized by prominent tubulopathy with apoptosis of tubular cells. Clinical and experimental evidence suggests that renal injury may be directly related to virus infection. Although HIV-1 is a polytropic and not solely lymphotropic pathogen, the susceptibility of renal cells to HIV-1 remains to be determined. This paper demonstrates in vitro the permissiveness of proximal tubular epithelial cells (PTEC) to HIV-1 and describes the effects of PTEC infection to explain the pathogenesis of tubular damage in vivo. The results indicate that PTEC express HIV-specific receptor and coreceptors and sustain virus replication. We observed that HIV-1 infection causes the death of tubular cells by triggering an apoptotic pathway involving caspase activation. Fas upregulation but not Fas ligand expression was found in the infected PTEC. However, after HIV-1 infection, tubular cells became susceptible to apoptosis induced through Fas stimulation. Caspase inhibition prevented the death of the infected PTEC in spite of persistent viral replication. These findings may explain the prominent histopathology of HIVassociated nephropathy and demonstrate that the apoptosis of nonlymphoid cells can be directly induced by HIV-1. ( $J$. Clin. Invest. 1998. 102:2041-2049.) Key words: HIV-associated nephropathy $\bullet$ tropism $\bullet$ apoptosis $\bullet$ caspases • Fas sensitization
\end{abstract}

\section{Introduction}

HIV-1 is a polytropic pathogen that, in addition to cells of the lymphoid organs, may infect cells of the gastrointestinal, vascular, and nervous systems (1-4). AIDS is characterized by cell loss in several organs and tissues, but the mechanisms of HIVinduced cytopathicity are still unclear $(1,5)$. The infected pa-

Address correspondence to Pier Giulio Conaldi, M.D., Ph.D., Department of Clinical and Biological Sciences, University of Insubria, Viale L. Borri 57, 21100 Varese, Italy. Phone: 39-332-278-311; FAX: 39-332-260-017; E-mail: pgiulio@working.it

Received for publication 18 March 1998 and accepted in revised form 21 October 1998

J. Clin. Invest.

(C) The American Society for Clinical Investigation, Inc. 0021-9738/98/12/2041/09 \$2.00

Volume 102, Number 12, December 1998, 2041-2049

http://www.jci.org tients may suffer a spectrum of renal damages (6). HIV-associated nephropathy (HIVAN) ${ }^{1}$ is a unique syndrome that affects up to $10 \%$ of the seropositive individuals and is characterized by glomerulosclerosis accompanied by prominent tubulointerstitial injury. Clinically, patients with HIVAN have nephrotic-range proteinuria with renal insufficiency, which does often rapidly progress to end-stage renal disease $(6,7)$. Acute renal failure secondary to tubular injury is also frequent in AIDS (6). In cases of HIVAN, viral antigens and genome have been demonstrated in microdissected renal tissues (8), but the permissiveness of renal cells to replication of HIV-1 is still controversial (9-14). The finding of apoptotic cells in glomeruli and especially in tubuli of HIV patients may suggest a possible mechanism of HIV-induced renal damage (15). This hypothesis is supported by the fact that renal tubular apoptosis occurs in transgenic mice expressing HIV genes (16). It is well established that apoptosis plays a relevant role in the pathogenesis of AIDS by contributing to $\mathrm{CD}^{+} \mathrm{T}$ cell depletion $(17,18)$. The enhanced susceptibility to apoptosis of T cells from HIVpositive individuals appears secondary to upregulation of Fas signaling or downregulation of Bcl-2 (19-21). Role and mechanisms of apoptosis in HIV-induced damage of nonlymphoid tissues are largely unknown.

The aim of this study was to investigate in vitro the permissiveness of human proximal tubular epithelial cells (PTEC) to HIV-1 productive infection and characterize the cytopathic effects (CPEs) of the infection, in order to evaluate the direct role of HIV-1 in the pathogenesis of tubular injury occurring in vivo. Our results demonstrate that PTEC express HIV-1 receptors and are permissive to virus replication, and indicate that HIV-1 infection causes apoptosis of tubular cells through activation of caspase proteases.

\section{Methods}

Reagents. Reagents were obtained from the following sources: $\mathrm{mAb}$ against human Fas (IgM, clone $\mathrm{CH}-11$, apoptosis inducing; Upstate Biotechnology, Lake Placid, NY); anti-human Fas mAb (IgG, clone ZB4, neutralizing; Upstate Biotechnology); anti-human Fas mAb (IgG, clone DX2; PharMingen, San Diego, CA); anti-human Fas ligand (FasL) mAb (clone NOK-1; PharMingen); anti-FasL rabbit IgG (N-20 and C-20; Santa Cruz Biotechnology, Santa Cruz, CA); FITC-conjugated goat anti-mouse IgG (Sigma Chemical Co., St. Louis, MO); anti-CD4 mAb (Sigma); FITC-conjugated anti-CD4 mAb (Becton Dickinson, San Jose, CA); anti-CXCR4 mAb (clone

1. Abbreviations used in this paper: CPE, cytopathic effect; FasL, Fas ligand; HIVAN, HIV-associated nephropathy; ICE, IL- $1 \beta$-converting enzyme; LTR, long terminal repeat; MC, mesangial cells; PE, phycoerythrin; p.i., post-infection; PI, propidium iodide; PTEC, proximal tubular epithelial cells; SFU, syncytium-forming unit. 
12G5; kindly provided by Dr. J. Hoxie, University of Pennsylvania, Philadelphia, PA [22]); phycoerythrin (PE)-labeled anti-CXCR4 $\mathrm{mAb}$ (clone 12G5; PharMingen); anti-CCR3 mAb (clone 7B11, obtained from NIBSC AIDS Reagent Project, ARP3099); anti-CCR5 $\mathrm{mAb}$ (clone 2D7; obtained from NIBSC AIDS Reagent Project, ARP3099); PE-labeled anti-CCR5 mAb (clone 2D7; PharMingen); anti-caspase-3 rabbit IgG (PharMingen); caspase-3 inhibitor (AcDEVD-CHO peptide; PharMingen); IL-1 $\beta$-converting enzyme (ICE) inhibitor (z-VAD- $\mathrm{CH}_{2} \mathrm{~F}$ peptide; Kamiya Biomedical, Seattle, WA); caspase inhibitor negative control (z-FA- $\mathrm{CH}_{2} \mathrm{~F}$ peptide; Kamiya Biomedical); and HIV-1 recombinant Tat, gp120, and gp41 (Intracel, London, UK); p24 antigen detection ELISA (DuPont, Cologno Monzese, Italy). Unless otherwise specified, chemicals and tissue culture reagents were from Sigma and molecular biology reagents were from Perkin-Elmer (Monza, Italy).

Renal cell cultures. Primary cultures of mesangial cells (MC) and PTEC were obtained from surgically removed kidneys of six different Caucasian patients, as described (23). The purity of the primary cultures was assessed on the basis of cell characterization, according to published criteria $(24,25)$. In brief, MC cultures grew as stellate cells in interwoven bundles and were positive for F-actin, detected with FITC-labeled phalloidin, and for smooth muscle-type myosin (Immunotech, Marseille, France). MC were negative for HLA-DR and leukocyte common antigen (CD45; Becton Dickinson), and for factor VIII-related antigen (FVIIIr:Ag; Nordic Immunology, Tilburg, The Netherlands). The ability of MC to contract after stimulation with angiotensin II and to phagocytize IgG-coated latex beads was analyzed as described (23). PTEC showed negative staining for FVIIIr:Ag, minimal staining for desmin, and marked staining with antibodies to cytokeratins and actin. PTEC were positive for alkaline phosphatase (determined by the naphtol AS-MX method) and showed enhanced cAMP production (Biotrak cAMP assay system; Amersham International, Buckinghamshire, UK) after stimulation with $100 \mathrm{nM}$ parathyroid hormone, but not with $1 \mathrm{mM}$ antidiuretic hormone.

Differentiated immortalized MC were obtained by infection of a pure primary culture with a hybrid Adeno5/SV40 virus $(3,26)$. Individual foci of immortalized cells were picked up, subcultured, and characterized according to phenotype. A differentiated MC line was selected and used between passages 20 and 35. An immortalized cell line of human PTEC, which has been characterized previously (25), was used (clone 5) to confirm and extend the experiments carried out with primary PTEC.

HIV infection. HIV-1 $1_{\mathrm{P} 1}$ is a syncytium-inducing T-tropic virus strain adapted to growth in T lymphoblastoid C8166 cells $(3,26)$. Virus stocks were prepared from clarified supernatants and titrated as syncytium-forming units (SFU) per milliliter. Cultures of primary and immortalized MC and PTEC were infected with HIV-1 (moi of 0.1) or mock-infected with control supernatant, at $48 \mathrm{~h}$ after plating. The inoculum was allowed to adsorb for $2 \mathrm{~h}$ at $37^{\circ} \mathrm{C}$; monolayers were washed three times and refed with fresh medium. A 50\% medium change was performed every $4 \mathrm{~d}$. HIV-1 infection was monitored by p24 antigen and infectivity testing in culture supernatants, and by detection of proviral DNA or viral RNA in infected cultures. Cell viability of the infected cells was evaluated by trypan blue exclusion test. Purified HIV-1 $1_{\mathrm{P} 1}$ was obtained by clarification $(3,000 \mathrm{~g}$ for $15 \mathrm{~min}$ at $\left.4^{\circ} \mathrm{C}\right)$ and precipitation of the virus $(10 \%$ polyethylene glycol- 8000 in PBS for $18 \mathrm{~h}$ at $\left.4^{\circ} \mathrm{C}\right)$. The pelleted virus was layered on a double sucrose cushion (1:2 of $60 \%$ sucrose and $20 \%$ sucrose) and centrifuged at $27,000 \mathrm{rpm}$ for $120 \mathrm{~min}$ at $4^{\circ} \mathrm{C}$ in a SW27 rotor (Beckman, Fullerton, CA). Banded virus was collected and frozen at $-70^{\circ} \mathrm{C}$. Thawed virus was diluted in medium and titrated as SFU/ml in C8166 cells (26).

PCR. Detection of HIV-1 long terminal repeat (LTR) and gag sequences was carried out as described $(3,26)$. PCR analysis of LTR sequences was carried out by amplification of $0.5 \mu \mathrm{g}$ of DNA of infected PTEC with primers SK28/29 (Research Genetics, Huntsville, AL). gag-specific sequence was amplified with primers SK100/104 (Research Genetics) from cDNA obtained by RT of $1 \mu \mathrm{g}$ of total
RNA treated with RNase-free DNase (Promega, Madison, WI). Detection of CD4 transcripts was performed by RT-PCR of a 438-bp fragment, as reported (26). cDNA was synthesized using a CD4-specific $3^{\prime}$ primer and subsequently amplified with $5^{\prime}$ and $3^{\prime}$ CD4 primers (Clontech, Palo Alto, CA) according to the manufacturer's instructions. RT-PCR analysis of CXCR4 transcripts in immortalized MC and PTEC was carried out using mRNA extracted from $10^{7}$ cells with PolyATract GTC ${ }^{\text {TM }}$ extraction buffer (Promega) and treated with RNase-free DNase. cDNA was synthesized using oligo d(T) primers and AMV-RT (Promega), again according to the manufacturer's instructions. PCR was performed on the cDNA using CXCR4-specific primers taken from the published human sequence (27; accession number M99293), which amplify a fragment of 1,078 bp. The program used for PCR was $94^{\circ} \mathrm{C}$ for $4 \mathrm{~min}$, followed by 40 cycles of $94^{\circ} \mathrm{C}$ for 1 min, $62^{\circ} \mathrm{C}$ for $1 \mathrm{~min}$, and $72^{\circ} \mathrm{C}$ for $1 \mathrm{~min}$, with a final step of $72^{\circ} \mathrm{C}$ for 20 min. Expression of FasL mRNA in uninfected or infected PTEC was evaluated by RT-PCR, as described (28; sense primer: $5^{\prime}$ CTGGGGATGTTTCAGCTCTTC-3'; antisense primer: 5'-CTTCACTCCAGAAAGCAGGAC-3'). cDNAs were synthesized by extension of antisense primer in a reaction mixture containing $2 \mu \mathrm{g}$ of total RNA digested by RNase-free DNase. The amplification was carried out by 35 cycles of $94^{\circ} \mathrm{C}$ for $30 \mathrm{~s}, 55^{\circ} \mathrm{C}$ for $1 \mathrm{~min}$, and $72^{\circ} \mathrm{C}$ for $1.5 \mathrm{~min}$. $\beta$-actin primers were used to check the integrity of all RNA samples. One-fifth of each reaction mixture was analyzed by electrophoresis through agarose gels and visualized by staining with ethidium bromide. The DNA size markers used were either the DNA marker V from Boehringer Mannheim (Mannheim, Germany) or the low-mass DNA ladder from GIBCO BRL (Life Technologies A.G., Basel, Switzerland).

Expression of membrane molecules. CD4 expression in primary $\mathrm{PTEC}$ and $\mathrm{MC}$ was tested by indirect immunofluorescence assay. Isolated and suspended renal cells were incubated with anti-CD4 mAb $\left(1 \mu \mathrm{g} / 10^{6}\right.$ cells $)$ for $30 \mathrm{~min}$ at room temperature. After washings, the cells were stained with FITC-labeled goat anti-mouse IgG for $30 \mathrm{~min}$ at room temperature, and examined with an epifluorescence Olympus BX60 microscope (Olympus Optical Co., Tokyo, Japan). Flow cytometry of CD4 expression was carried out by incubating $10^{6}$ renal cells with $1 \mu \mathrm{g}$ of FITC-conjugated specific antibody in PBS $/ 0.1 \%$ sodium azide for $30 \mathrm{~min}$ at room temperature. After washings, cell suspensions were fixed in $0.2 \%$ paraformaldehyde and analyzed with a flow cytometer (FACScan ${ }^{\circledR}$; Becton Dickinson). Surface expression of CXCR-4 was determined by incubating immortalized PTEC or MC $\left(3 \times 10^{6}\right)$ with $2 \mu \mathrm{g}$ of $12 \mathrm{G} 5 \mathrm{mAb}$ for $15 \mathrm{~min}$ at room temperature in $100 \mu \mathrm{l}$ of PBS $+1 \%$ BSA. The same procedure was used to evaluate CCR3 and CCR5 expression using 7B11 and 2D7 mAbs, respectively. The cells were washed twice with PBS and incubated with FITC-labeled goat anti-mouse IgG for $15 \mathrm{~min}$ at room temperature. After two washings with PBS, the cells were analyzed (FACScan ${ }^{\circledR}$ ). To assess coexpression of CD4 and chemokine receptors, immortalized PTEC were stained with FITC-labeled anti-CD4 mAb and antibodies specific for CXCR-4 and CCR5 directly conjugated with PE. For analysis of surface Fas expression, $10^{6}$ mock-infected and HIVinfected PTEC were incubated with $0.5 \mu \mathrm{g}$ of anti-human Fas IgG (DX2 $\mathrm{mAb}$ ) in PBS $/ 0.1 \%$ sodium azide for $60 \mathrm{~min}$ at $4^{\circ} \mathrm{C}$. Then, the cells were washed and incubated with FITC-conjugated goat antimouse $\operatorname{IgG}$ for $30 \mathrm{~min}$ at $4^{\circ} \mathrm{C}$. After washings, cell suspensions were fixed in $0.2 \%$ paraformaldehyde and flow cytometric analysis was performed. The same procedure was used to detect membrane-bound FasL by using a specific mAb (NOK-1) at the concentration of $1 \mu \mathrm{g} /$ $10^{6}$ cells (29). In all experiments, isotype-matched irrelevant antibodies were included as control.

Apoptosis measurement. PTEC were incubated with propidium iodide (PI) followed by flow cytometry analysis, as described (30). In brief, $10^{6}$ cells were incubated for $4 \mathrm{~h}$ at $4^{\circ} \mathrm{C}$ in $2 \mathrm{ml}$ hypotonic solution containing $50 \mu \mathrm{g} / \mathrm{ml}$ PI, $0.1 \%$ sodium citrate, $0.1 \%$ Triton X-100, and $20 \mu \mathrm{g} / \mathrm{ml}$ DNase-free RNase A. Cells with subdiploid DNA content (sub- $\mathrm{G}_{0} / \mathrm{G}_{1}$ peak) were considered apoptotic cells. Morphological features of apoptotic cell nuclei were also evaluated by PI staining 
(31). Cells were fixed with $2 \%$ formaldehyde in PBS for $10 \mathrm{~min}$ at $4^{\circ} \mathrm{C}$, treated with PI solution for $20 \mathrm{~min}$ at room temperature, and then examined with an epifluorescence Olympus BX60 microscope. The apoptotic state of the cells was evaluated by differential uptake of acridine orange and ethidium bromide (31). Cells $\left(5 \times 10^{4}\right.$ in $25 \mu \mathrm{l}$ of PBS) were stained with $1 \mu \mathrm{l}$ of a mixture of $100 \mu \mathrm{g} / \mathrm{ml}$ acridine orange and $100 \mu \mathrm{g} / \mathrm{ml}$ ethidium bromide (1:1). Observed through wideband FITC filters, cells in the early stages of apoptosis are characterized by condensed or fragmented bright green chromatin, and late apoptotic cells by condensed or fragmented bright orange chromatin.

Cell viability assay. PTEC were seeded in 24-well microtiter plates at $5 \times 10^{4}$ cells/well. The cultures were infected or mock-infected as described above. After incubation under different conditions, dried monolayers were treated with $0.75 \%$ crystal violet in a solution of $50 \%$ ethanol, $0.25 \% \mathrm{NaCl}$, and $1.75 \%$ formaldehyde (32). After washing, the dye was eluted with 1\% SDS in PBS and the absorbance was read at $595 \mathrm{~nm}$ with an ELISA reader. Cell viability was expressed as percentage of uninfected controls. Assays were also performed with PTEC cultures treated with Tat $(1 \mu \mathrm{g} / \mathrm{ml})$, gp120 $(1 \mu \mathrm{g} /$ $\mathrm{ml})$, or gp41 $(1 \mu \mathrm{g} / \mathrm{ml})$ to evaluate the effect of these viral molecules on PTEC viability. For apoptosis induction experiments (33), antiFas agonistic IgM $(100 \mathrm{ng} / \mathrm{ml})$ or supernatants of COS cells producing human FasL ( $4 \mathrm{~d}$ after transfection) and mock-transfected COS cells were added to PTEC at day 2 post-infection (p.i.). For apoptosis inhibition experiments, infected PTEC were treated with anti-Fas neutralizing $\operatorname{IgG}(1 \mu \mathrm{g} / \mathrm{ml})$ at days 2 and 4 p.i., or with caspase inhibitors (caspase-3 inhibitor: $100 \mu \mathrm{M}$; ICE protease blocking peptide: $0.1-100$ $\mu \mathrm{M}$; caspase inhibitor negative control: $100 \mu \mathrm{M}$ ) at days 1 and 4 p.i.

Western blot analysis. To identify the expression of FasL, transient expression of cDNA encoding full-length human FasL, kindly provided by Dr. H. Yagita (Juntendo University, Tokyo, Japan [29]), was performed in COS cells transfected by electroporation at $250 \mathrm{~V} / 960$ $\mu \mathrm{F}$ (Electroporator II; Invitrogen, Carlsbad, CA). The cells were lysed 5-7 d after transfection at $4^{\circ} \mathrm{C}$ for $1 \mathrm{~h}$ in a lysis buffer $(50 \mathrm{mM}$ Tris- $\mathrm{HCl}, \mathrm{pH} 8.3$, containing 1\% Triton X-100, $10 \mu \mathrm{M}$ PMSF, $10 \mu \mathrm{g} /$ $\mathrm{ml}$ leupeptin, and $100 \mathrm{U} / \mathrm{ml}$ aprotinin). Similarly, cell pellets were obtained from uninfected or HIV-infected PTEC cultures and then lysed. After centrifugation of the lysates at $15,000 \mathrm{~g}$, the supernatants were quantitated for protein content by the Bradford method. Aliquots containing $100 \mu \mathrm{g}$ of protein per lane were subjected to SDS/10\%
PAGE under nonreducing or reducing (5\% 2-mercaptoethanol) conditions and electroblotted onto nitrocellulose membrane filters. The blots were blocked with $5 \%$ nonfat milk in $20 \mathrm{mM}$ Tris- $\mathrm{HCl}, \mathrm{pH} 7.5$, $500 \mathrm{mM} \mathrm{NaCl}$ plus $0.1 \%$ Tween (TBS-T). The membranes were subsequently incubated overnight at $4{ }^{\circ} \mathrm{C}$ with polyclonal rabbit antibody against amino terminus (N-20) or carboxyl terminus (C-20) of FasL, at a concentration of $500 \mathrm{ng} / \mathrm{ml}$. After extensive washing with TBS-T, the blots were incubated for $1 \mathrm{~h}$ at room temperature with peroxidase-conjugated protein A (200 ng/ml; Amersham), washed with TBS-T, developed with ECL detection reagents (Amersham) for 1 min and exposed to X-Omat film (Eastman Kodak Co., Rochester, NY). To reveal caspase-3 activation, aliquots of the lysates obtained from uninfected or infected PTEC were subjected to SDS-PAGE and electroblotting, as described. Western blot analysis of proenzyme and cleavaged subunits was performed by using a 1:1,000 dilution of a polyclonal rabbit anti-caspase- 3 antibody and revealed by ECL, as reported above.

\section{Results}

HIV-1 induces productive infection of renal tubular cells. Primary cultures of PTEC and MC were infected with HIV-1 $1_{\mathrm{P} 1}$, a syncytium-inducing virus strain adapted to $\mathrm{T}$ cell lines but able to infect nonlymphoid cells $(3,26)$. HIV-1 replication in PTEC was demonstrated by measurement of p24 content in culture supernatants (Fig. $1 a$ ) and by detection of both proviral DNA and viral genomic RNA in the infected cells (Fig. $1 b$ ). The establishment of HIV-1 productive infection was confirmed by titration of infectious viral progeny released by PTEC cultures (mean titer of $10^{2.5} \mathrm{SFU} / \mathrm{ml}$ at peak level). Active replication of HIV-1 $1_{\mathrm{P} 1}$ was also detected in MC; kinetics and grade of virus production were similar to those found in PTEC (Fig. 1a). However, the effect of HIV-1 infection was different in the two cell types. Whereas viral replication in MC caused only minor CPEs, HIV-infected PTEC showed, in contrast, a progressive reduction of cell viability and underwent death within 7-14 d p.i. (Fig. $1 a$ ). The evidence achieved with primary cul- a

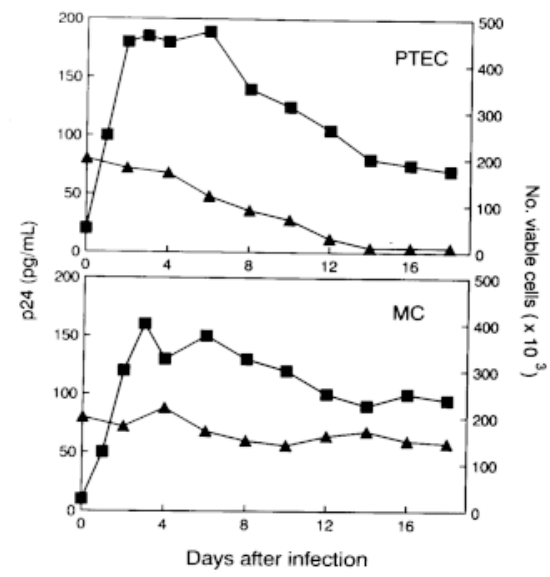

b

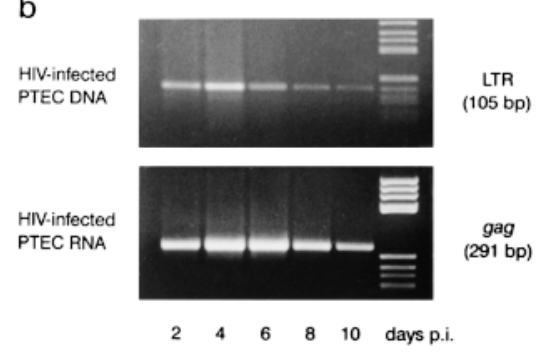

C

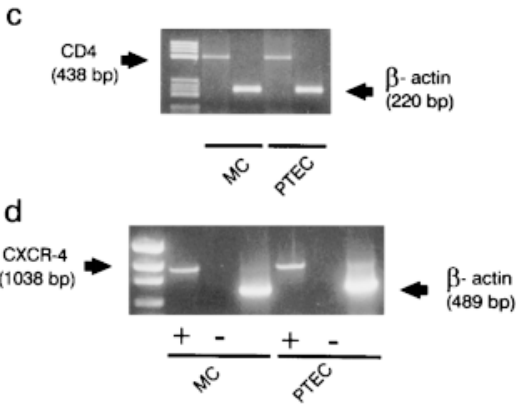

Figure 1. Susceptibility of human renal cells to HIV infection. (a) Kinetics of p24 levels (filled boxes) and cell viability (filled triangles) in cultures of PTEC and MC infected with HIV-1. Cell viability is expressed as number of viable cells per culture. Consistent results were obtained with renal cells derived from six different donors. The same outcome of HIV infection has been observed using immortalized MC and PTEC lines. (b) Detection of HIV-1 nucleic acids in infected PTEC cultures. Amplification of LTR sequences was performed using genomic DNA isolated from infected PTEC at different times p.i. Detection of gag was carried out by RT-PCR on total RNA obtained at the same time points as above (size markers: DNA marker V from Boehringer Mannheim). (c) Detection by RT-PCR of CD4 transcripts in immortalized MC and PTEC lines (size markers: DNA marker V). (d) Detection by RT-PCR of CXCR-4 transcripts in immortalized PTEC and MC lines (size markers: low-mass DNA ladder from GIBCO BRL). 
tures of MC and PTEC was confirmed by infecting renal cell lines that retained phenotypic and functional characteristics associated with differentiated glomerular mesangial and tubular epithelial cells, respectively $(23,25)$.

RT-PCR analysis of primary cultures revealed that both PTEC and MC can synthesize mRNAs specific for CD4, the major HIV receptor, and for CXCR-4, a chemokine receptor identified as the main fusion cofactor of T lymphotropic HIV-1 strains $(34,35)$. This evidence was confirmed using immortalized cell lines of PTEC and MC to avoid contamination of nonrenal cells (Fig. 1, $c$ and $d$ ). By immunofluorescence tests, we found that $15-25 \%$ of suspended cells from primary PTEC and MC cultures showed positive staining for CD4. Flow cytometry confirmed the presence of HIV receptors on the surface of tubular cells and MC. Figs. 2 and 3 show FACScan ${ }^{\circledR}$ analysis of immortalized PTEC, that were 55\% ( \pm 11$)$ positive for CD4 and 15\% ( \pm 2$)$ positive for CXCR-4. MC resulted as positive $45 \%( \pm 15)$ and $14 \%( \pm 3)$, respectively. It must be noted that lower levels of CCR3 $(6 \pm 2 \%)$ and CCR5 $(7 \pm 4 \%)$ chemokine receptors were detected on PTEC surface (Fig. 3). By two-color staining technique, we found that $8 \%( \pm 4)$ of PTEC are double positive for CD4 and CXCR-4, whereas 5\% $( \pm 3)$ of these cells coexpress CD4 and CCR5.

$H I V-1$ infection induces apoptosis of renal tubular cells. Features of the HIV-infected PTEC observed by light microscopy were consistent with changes characteristic of apoptosis: rounding and detachment of the cells with fragmentation and shrinking of nuclei. To determine whether HIV-1 does induce apoptosis of renal tubular cells, PTEC were infected with HIV- $1_{\mathrm{P} 1}$, harvested at different time points p.i., and examined for DNA content in comparison with mock-infected cells. Cytofluorometric analysis revealed the presence of hypodiploid cells from days 4-5 p.i. in the infected cultures (Fig. 4). By day 10 p.i., the percentage of apoptotic cells was $60-80 \%$ and by $14 \mathrm{~d}$ p.i. all the cells of infected PTEC cultures underwent detachment and death. Evidence of CPE was not found in mock-infected PTEC cultures. Apoptosis was confirmed by direct observation of chromatin condensation and nuclear frag-

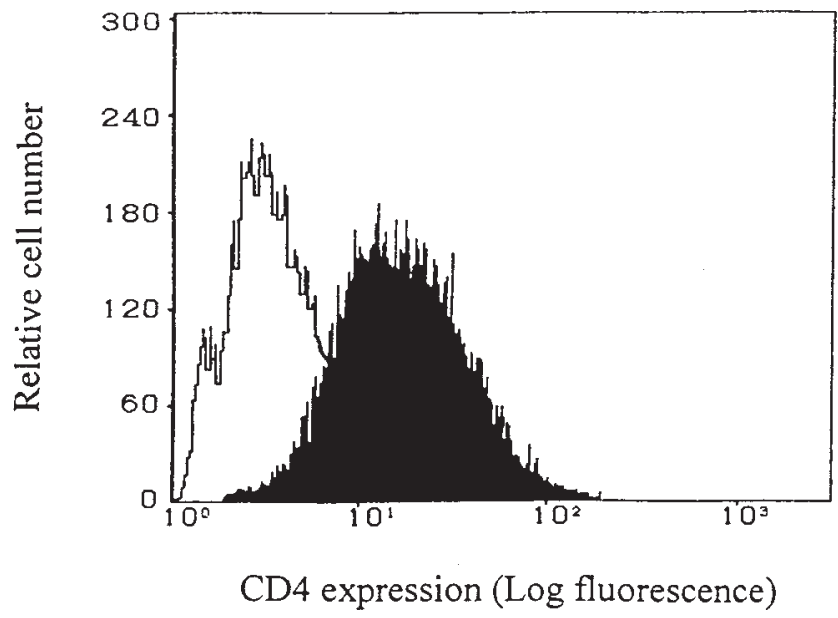

Figure 2. Cytofluorometric analysis of membrane CD4 in renal tubular epithelial cells. Immortalized PTEC were stained with FITC-conjugated anti-CD4 mAb (shaded histogram) as reported in Methods. Negative control (empty histogram) was PTEC incubated with FITCconjugated isotype-matched irrelevant $\mathrm{mAb}$.

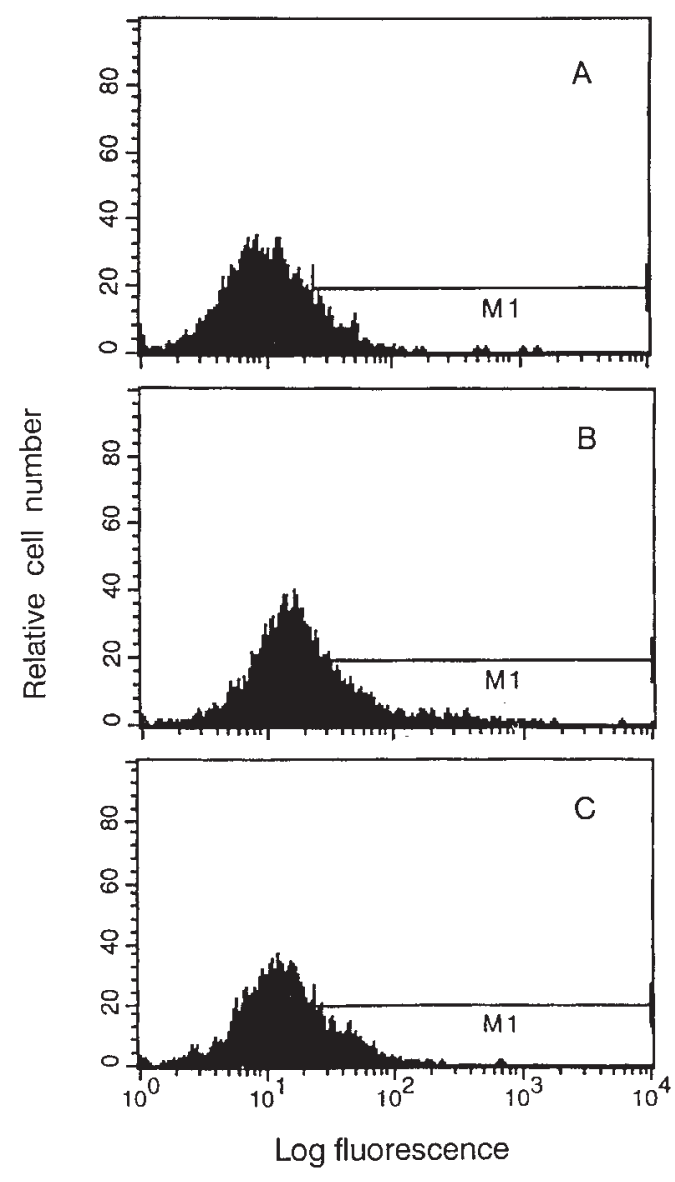

Figure 3. Cytofluorometric analysis of chemokine receptors in renal tubular epithelial cells by indirect immunofluorescence. $(A)$ FACScan ${ }^{\circledR}$ profile of immortalized PTEC incubated with isotype-matched control $\mathrm{mAb}$ and FITC-labeled goat anti-mouse IgG. Surface expression of CXCR-4 $(B)$ and CCR5 $(C)$ was evaluated by staining PTEC with specific $\mathrm{mAbs}$, as reported in Methods.

mentation with PI staining (Fig. $5 a$ ). Time course studies of the differential uptake of fluorescent DNA binding dyes revealed the presence of early apoptotic cells from day 4 p.i. and showed the progressive increase of the apoptotic changes in parallel with the lasting of PTEC infection (Fig. $5 b$ ). The activation of caspases is a critical event in the proteolytic cascade elicited by apoptotic stimuli (36). Indeed, by Western blot analysis of HIV-infected PTEC, we detected activated caspase-3 (Fig. 6), an enzyme implicated in the effector phase of apoptosis of different cell types (37). The exposure of tubular cells to gp120, gp41, and Tat (viral components that are known to induce apoptosis in other experimental models [30, 38, 39]) failed to impair the viability of PTEC cultures, whereas tubular cells underwent apoptosis when the infection was performed with purified $\mathrm{HIV}-1_{\mathrm{P} 1}$ as the inoculum (data not shown). These results indicate that apoptosis is a direct effect of HIV-1 productive infection of renal tubular epithelial cells.

HIV-1 infection induces overexpression of Fas and sensitization to Fas signaling in renal tubular cells. Several members of the TNF receptor superfamily regulate cell survival (40). Recently, it has been reported that human tubular epithelial cells express Fas, a 43-kD member of TNF receptor family $(41,42)$. In this study we found that $70-80 \%$ of the cells of PTEC line 


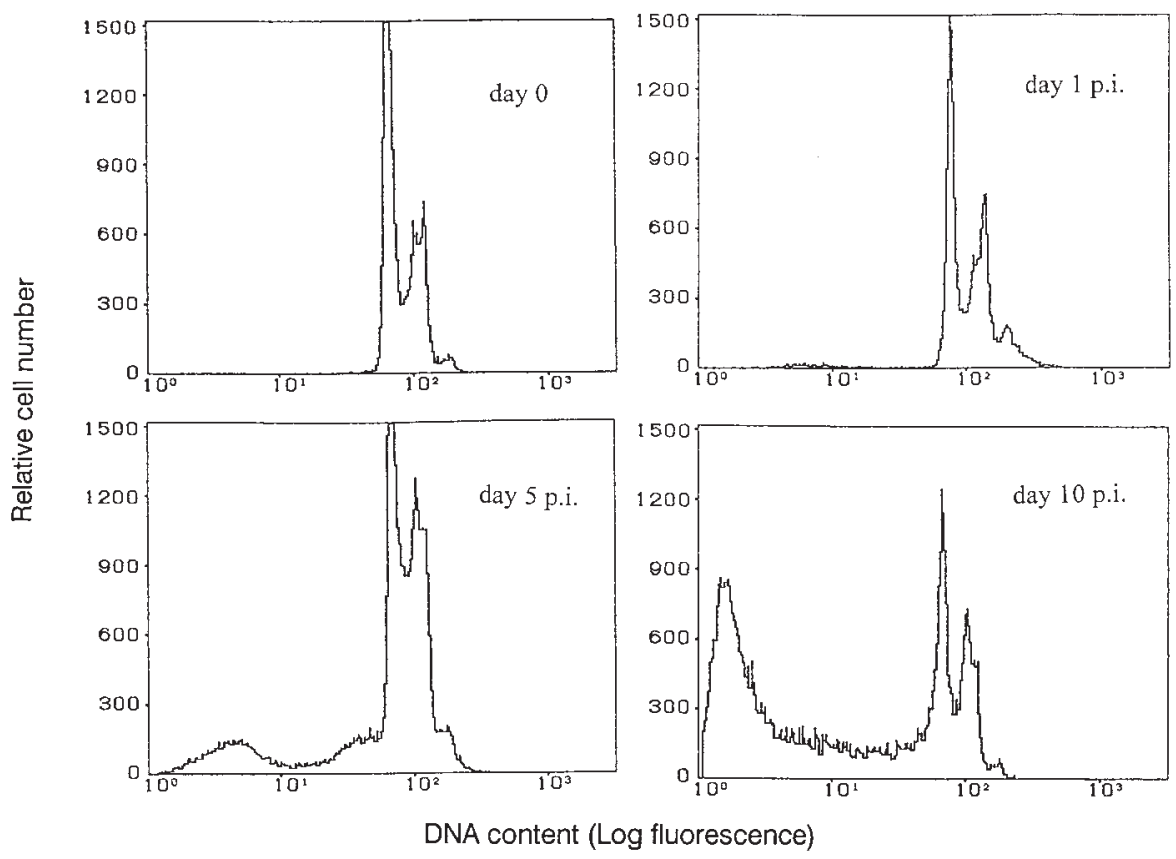

Figure 4. HIV-induced apoptosis of renal tubular epithelial cells. DNA histograms of infected PTEC taken at the indicated time points p.i. and stained with PI to evaluate the DNA content. Apoptotic cells are characterized by low DNA stainability and appear below the $G_{1}$ peak in the distribution At day 10 p.i., the proportion of hypodiploid cells in HIV-infected PTEC cultures was $70 \%$ (range $60-85 \%$ ) versus $1-3 \%$ in mock-infected PTEC cultures. exhibited a positive staining for Fas, but HIV-1 infection induced in the tubular cells a prominent upregulation of Fas from days 2-3 p.i. (Fig. 7 a). On the contrary, no evidence of membrane FasL (43) was found in HIV-infected PTEC with FACScan $^{\circledR}$ and Western blot analysis (Fig. $7 b$ ), and neither expression of FasL mRNA was detected by RT-PCR in tubular cells after infection (not shown). The treatment of PTEC cultures with anti-Fas blocking antibody did not cause a significant reduction of HIV-induced CPE. In fact, the mortality of HIV-infected PTEC at day 10 p.i. was $70 \pm 15 \%$ in the case of untreated cultures, and $60 \pm 12 \%(P=\mathrm{ns})$ in cultures of tubular cells added with anti-Fas mAb. According to a recent report (42), uninfected PTEC were resistant to Fas stimulation, as determined by measurement of cell viability after treatment with specific IgM-inducing Fas ligation (Fig. 8). In contrast, the addition of the anti-Fas agonistic antibody to the infected PTEC cultures at day 2 p.i. did relevantly increase and precipitate apoptotic changes of tubular cells, in comparison with the spontaneous kinetics of HIV-induced apoptosis (Fig. 8). Similar results have been obtained treating HIV-positive cultures

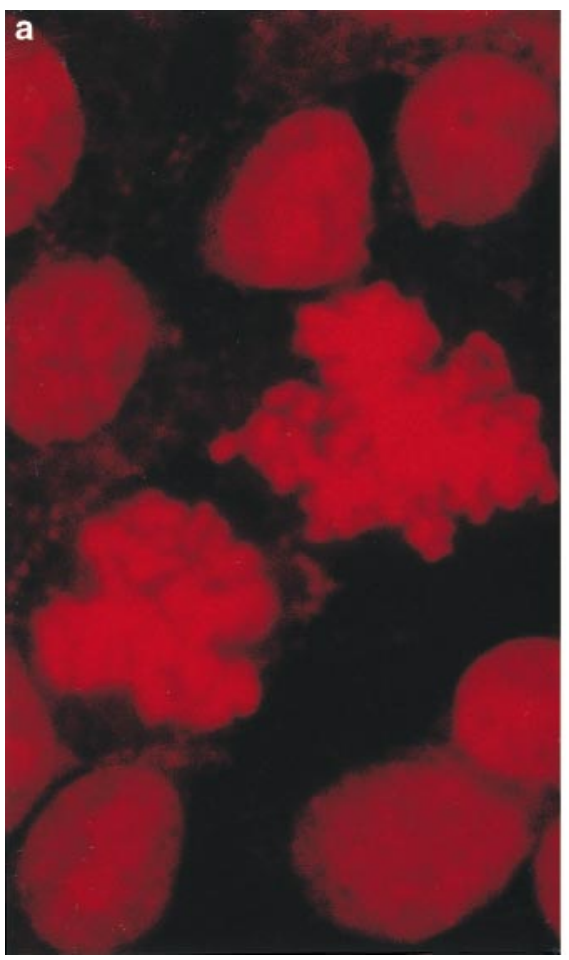

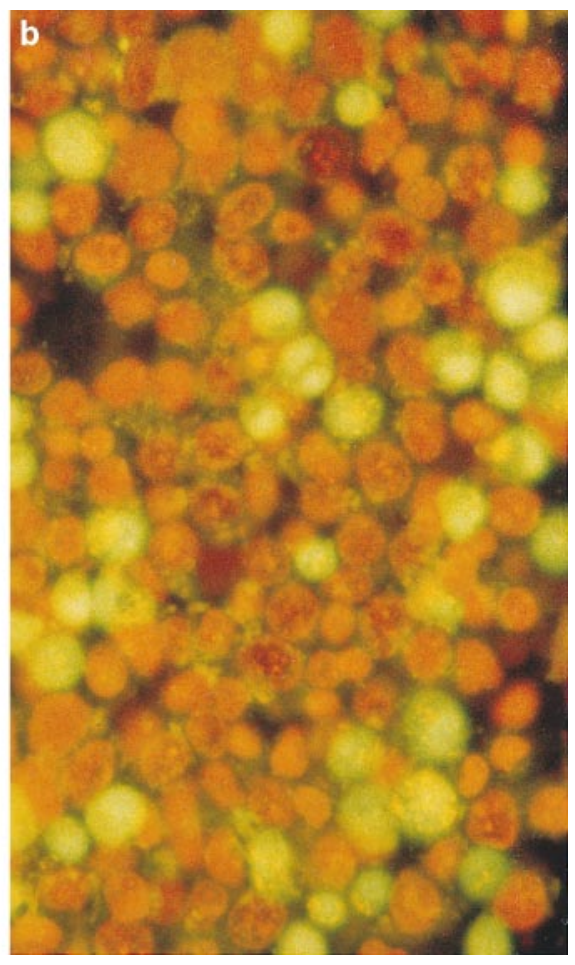

Figure 5. Direct visualization of HIVinduced apoptosis of renal tubular epithelial cells. (a) PTEC were stained with PI at day 5 p.i. Apoptotic cells show chromatin condensation and fragmentation of nuclear material (original magnification, $\times 600)$. (b) Quantification of cell viability and apoptotic index by acridine orange/ethidium bromide uptake of infected PTEC at $10 \mathrm{~d}$ p.i. HIV-induced death of tubular cells is characterized by absence of lysis, cell detachment, and nuclear modification: late apoptotic PTEC show orange nuclei with bright areas of condensed chromatin (original magnification, $\times 200)$. 


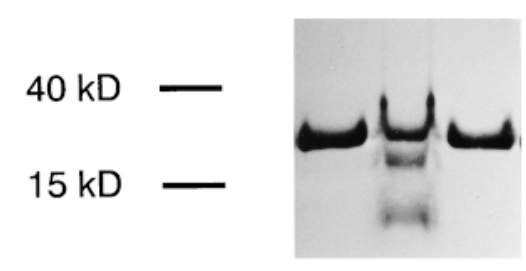

infected PTEC at day 4

p.i.; lane 3 , uninfected PTEC. Inactive proenzyme $(32 \mathrm{kD})$ was found in all samples. The activated form of caspase- 3 , consisting of large (17-22 kD) and small (10-12 kD) subunits, was detected in HIVinfected PTEC undergoing apoptosis.

with supernatants of COS cells transfected with human FasL cDNA, but not with mock-transfected COS supernatants (data not shown). These findings indicate that HIV-1 productive infection can sensitize the tubular epithelial cells to Fas-mediated programmed cell death.

Caspase inhibition prevents apoptosis of HIV-infected renal tubular cells without affecting viral replication. Since the inhibition of caspase functions has been shown to block the development of programmed cell death (44), we evaluated whether HIV-induced PTEC apoptosis could be prevented by treatment with $\mathrm{z}-\mathrm{VAD}-\mathrm{CH}_{2} \mathrm{~F}$ peptide, an irreversible caspase inhibitor (45). As shown in Fig. $9 a$, the death of HIV-infected tubular cells was prevented by peptide addition to the infected cultures at day 1 p.i. Similar results have been obtained using Ac-DEVD-CHO peptide specific for caspase-3 (46). Western blot analysis of HIV-infected PTEC treated with this peptide demonstrated an effective inhibition of caspase-3 activation (data not shown). By flow cytometry or light microscopy, apop-

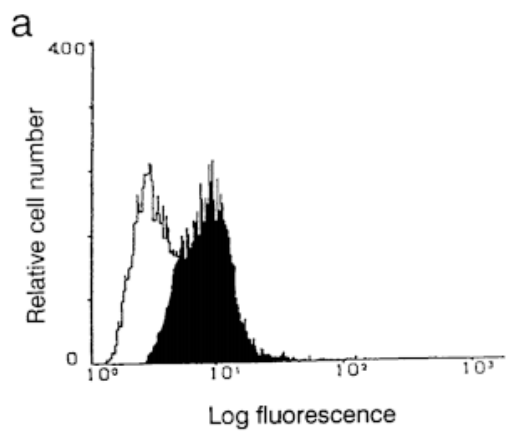

b

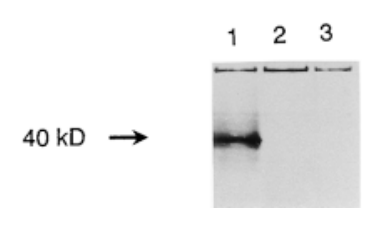

Figure 7. Evaluation of the involvement of Fas/ FasL pathway in HIVinduced apoptosis of infected renal tubular epithelial cells. (a) Cytofluorometric analysis of Fas expression in uninfected (empty histogram) and HIV-infected (shaded histogram) PTEC by indirect immunofluorescence. Negative controls were cells stained with isotype-matched irrelevant $\mathrm{mAb}$ as primary antibody (not shown). (b) Western blot analysis of FasL expression. Cell lysates of COS cells transfected with human

FasL full-length cDNA were used as positive control (lane 1). Cell lysates of uninfected PTEC and HIV-infected PTEC at day 4 p.i. were run in lanes 2 and 3, respectively. Samples of HIV-infected PTEC taken at different times p.i. were constantly negative for FasL expression. SDS-PAGE was performed in reducing conditions; Western blots were stained with anti-FasL C-20 antibody (see Methods).

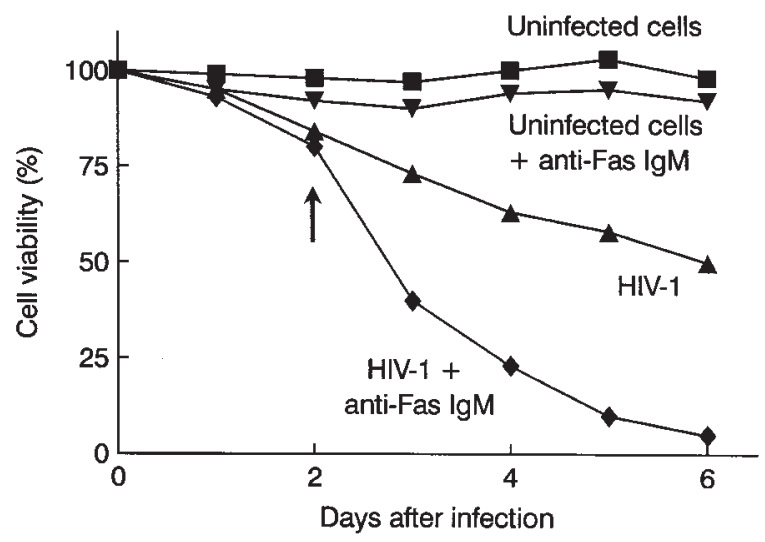

Figure 8. Sensitization of HIV-infected tubular epithelial cells to Fasmediated apoptosis. The treatment at day 2 p.i. (arrow) with agonistic anti-Fas IgM $(100 \mathrm{ng} / \mathrm{ml})$ enhanced programmed cell death in infected PTEC. As a control, treatment with anti-Fas IgM did not influence cell viability of uninfected PTEC.

totic changes or manifestations of overt CPEs were not detected in the infected PTEC cultures treated with caspase inhibitors. Modifications of growth rate and cell viability were not observed in uninfected PTEC cultures after inhibition of caspase activity. Fig. $9 b$ demonstrates that treatment with z-VAD- $\mathrm{CH}_{2} \mathrm{~F}$ peptide blocks $\mathrm{HIV}$-induced apoptosis in a dose-dependent fashion. The addition of $\mathrm{z}-\mathrm{FA}-\mathrm{CH}_{2} \mathrm{~F}$ peptide, caspase inhibitor negative control, did not influence PTEC commitment to death caused by HIV infection. Upon inhibition of caspases, we did not observe relevant effects on virus replication, measured in terms of both extracellular p24 levels and production of infectious progeny from PTEC cultures at the early phase (up to day 4 p.i.) of the infection. Instead, at day 10 p.i. reduced contents of p24 were detected in HIVinfected cultures undergoing apoptosis $(24 \mathrm{pg} / \mathrm{ml})$ in respect to infected cultures treated with caspase inhibitors $(155 \mathrm{pg} / \mathrm{ml})$. This evidence can be explained by the reduction of the viable cells actively replicating HIV-1. These findings indicate that caspase inhibition can prevent the death of HIV-infected tubular cells by blocking the apoptotic pathway activated by HIV infection without interfering with virus replication.

\section{Discussion}

HIV-associated renal diseases affect up to $10 \%$ of the infected individuals, but their prevalence is probably underestimated and is going to increase, since prolonged survival of HIV patients is being achieved with antiviral therapy (47). Tubular damage is a hallmark of renal injury in HIV-1 infection. Both acute renal failure and HIVAN developing end-stage renal disease are characterized by severe tubulopathy with degenerative and apoptotic changes of tubular cells $(6,15)$. Studies on virus detection in renal tubuli of HIVAN patients reported conflicting results $(8,9,12,48)$. Recently, renal epithelial cells were infectable in particular experimental conditions, i.e., after exposure to high titers of primary HIV-1 isolates from children with HIVAN (14). Indeed, our results demonstrate that PTEC are susceptible to HIV-1 replication and undergo apoptosis as a consequence of the virus infection. 


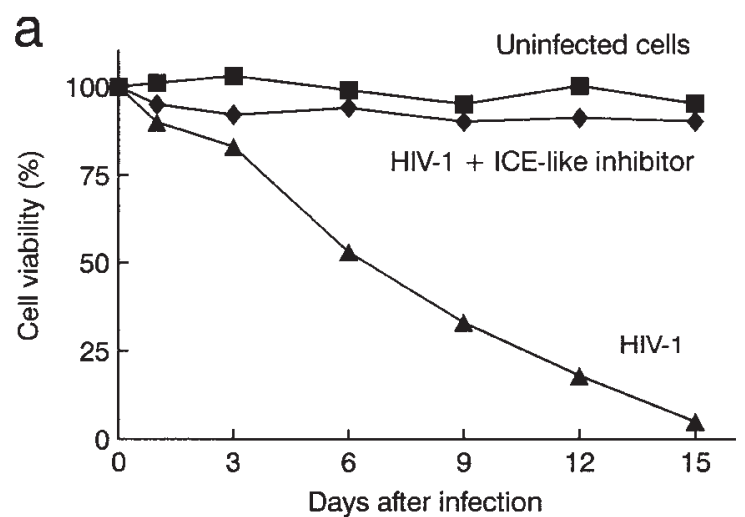

b

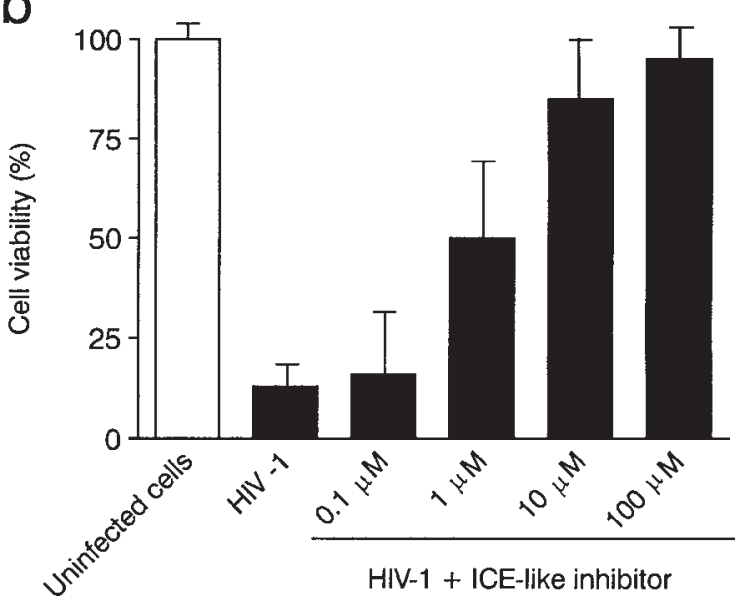

Figure 9. Prevention of HIV-induced apoptosis of infected renal tubular epithelial cells by caspase inhibition. (a) Effect of caspaseinhibiting peptide $\mathrm{z}-\mathrm{VAD}-\mathrm{CH}_{2} \mathrm{~F}(100 \mu \mathrm{M})$ on viability of HIVinfected PTEC cultures. This treatment did not modify the viability and growth rate of uninfected PTEC (not shown). (b) Dose dependence of the antiapoptotic activity of caspase inhibitor on HIVinduced death of PTEC. Cell viability was evaluated at day 12 p.i.

Generally, HIV-1 tropism is restricted at the level of the virus entry (49). Recent studies demonstrate that expression of a high-affinity receptor and an appropriate coreceptor is necessary to render target cells permissive for attachment and penetration of the different HIV-1 strains (50). The permissiveness of PTEC and MC to HIV-1 $1_{\mathrm{P} 1}$ can be explained by cell expression of CD4 and CXCR-4, the major coreceptor for T-tropic virus strains $(34,35)$. The detection of CCR5 and CCR3 chemokine receptors on the cell surface of PTEC suggests that tubular cells can also be susceptible to M-tropic or dual-tropic HIV-1 strains $(51,52)$. This finding accounts for the recent report that all the primary viral isolates capable of infecting renal epithelial cells could infect macrophages (14).

In this study we observed that HIV-1 can actively replicate both in PTEC and MC, but the outcome of viral infection is different in these two renal cell types. Whereas infected MC did not develop overt CPE, HIV-1 infection did irreversibly cause the death of PTEC by apoptosis. This finding may explain the histopathological features of HIV-induced kidney damage. In fact, both acute renal failure and HIVAN are characterized by severe tubulopathy with prominent apoptotic features, tubular atrophy and formation of microcystic dilatation of tubuli $(6,7,15)$. Our results demonstrate that apoptosis and loss of tubular cells can occur as a direct effect of HIV-1 infection of these cells.

AIDS is characterized by cell injury in several organs and tissues $(1,53)$. A body of evidence shows that programmed cell death plays a pivotal role in $\mathrm{CD} 4^{+}$lymphocyte depletion $(17$, 18). Recent studies point out that apoptosis of nonlymphoid cells (neurons, astrocytes, and endothelial cells) may also contribute to the development of prominent pathologies of AIDS, such as brain damage and thrombotic thrombocytopenic purpura $(54,55)$. In these cases, the apoptotic changes have been related to soluble factors produced during virus infection. Our results indicate that HIV-1 can directly induce apoptosis of parenchymal epithelial cells susceptible to productive infection.

Programmed cell death is considered a mechanism of tubular damage in many different renal diseases, but the pathways involved in the apoptotic response of renal cells are still under investigation (56). In this study we tested the possibility that Fas/FasL apoptotic pathway was operative in HIV-induced killing of renal tubular cells. Our results confirmed that PTEC express Fas (43), a membrane protein transducing a death signal in permissive cells upon ligation, but FasL activity was not found in HIV-infected cultures, neither Fas blockade with a neutralizing antibody significantly reduced apoptosis of HIVinfected PTEC. However, whereas normal tubular cells were resistant to Fas stimulation as reported (43), HIV-infected PTEC showed Fas overexpression and sensitization to apoptotic pathway elicited by FasL or Fas cross-linking antibodies. It is of note that a similar condition may occur in vivo. In HIV-infected patients FasL-bearing lymphoid cells may establish trans-interaction with Fas-upregulated tubular cells (21). Moreover, the enhanced glomerular permeability of HIVAN patients may expose PTEC to a high concentration of filtered immunoglobulins. Anti-Fas autoantibodies and anti-gp120 IgG cross-reacting with Fas were detected recently in HIV patients $(57,58)$. Thus, Fas agonistic antibodies could represent the luminal apoptotic triggers for PTEC already sensitized to Fas signaling after HIV entry through basolateral surfaces. Our results indicate that HIV infection of renal tubular cells causes intracellular events allowing Fas sensitization and leading to the activation of programmed cell death. This conclusion is consistent with the finding of tubular apoptosis in transgenic mice expressing HIV genes (16). Self-association of death domain of Fas can lead to spontaneous signaling, independent of ligand, in case of failure of the intracellular mechanisms restricting Fas aggregation (59). Further studies are needed to clarify whether apoptosis of HIV-infected PTEC overexpressing Fas is caused by this phenomenon or by induction of other apoptotic events like ceramide production $(60,61)$.

Caspases play a central role in the core signaling pathway of apoptosis (36). It was reported recently that the differential expression of a member of this protease family can modulate the susceptibility to apoptosis of lymphocytes taken from HIVpositive patients (62). In our study we detected caspase-3 activation in HIV-infected PTEC undergoing apoptosis. On the other hand, we found that the timely inhibition of caspase activity prevents the development of apoptotic changes and preserves the viability of the infected tubular cells. Virus production was not impaired in PTEC cultures treated with peptide-based inhibitors, in agreement with the results obtained blocking apoptosis of HIV-infected lymphoid cells $(63,64)$. Thus, the inhibition of caspase appears to prevent virus-induced death of 
tubular cells without altering virus replication. The beneficial effect of cell survival obtained by arresting apoptosis in HIVinfected cell populations may provide a rationale for combining antiviral drugs with antiapoptotic agents in order to clear infection and also to preserve tissue integrity and functions at the same time (65).

In conclusion, we found that both human mesangial and tubular cells are permissive to HIV-1 entry and are able to sustain active replication of the virus. However, a distinct effect on cell viability was observed in these two renal cell types after infection. HIV-1 kills tubular cells by triggering apoptosis with activation of caspases. Fas/FasL interactions are not involved in this phenomenon, but HIV-infected PTEC are sensitized to Fas-mediated apoptosis. Caspase inhibition rescues the infected PTEC from commitment to death in spite of the persistence of HIV replication. Since these findings are consistent with the histopathological features of tubulopathy in HIVinduced renal injury, our results may explain the pathogenesis of this common condition in the infected patients and suggest novel therapeutic hints.

\section{Acknowledgments}

The authors would like to thank Dr. H. Yagita (Juntendo University) for the generous gift of human FasL full-length cDNA, Dr. J. Hoxie (University of Pennsylvania) for providing 12G5 mAb, and the NIBSC AIDS Reagent Project (Resource Manager, Dr. H. Holmes), funded by EU Programme EVA, for providing the anti-CCR3 and anti-CCR5 mAbs.

This work was supported by grants from the Istituto Superiore di Sanità, Rome, Italy (AIDS Grant 40A.1.03 and AIDS Grant 30A.0.09) and by the Italian Ministry for Scientific Research (funds $40 \%)$.

\section{References}

1. Levy, J.A. 1993. Pathogenesis of human immunodeficiency virus infection. Microbiol. Rev. 57:183-289.

2. Yahi, N., S. Baghdiguian, H. Moreau, and J. Fantini. 1992. Galactosyl ceramide (or a closely related molecule) is the receptor for human immunodeficiency virus type 1 on human colon epithelial HT29 cells. J. Virol. 66:4848-4854.

3. Conaldi, P.G., C. Serra, A. Dolei, B. Basolo, V. Falcone, G. Mariani, P. Speziale, and A. Toniolo. 1995. Productive HIV-1 infection of human vascular endothelial cells requires cell proliferation and is stimulated by combined treatment with interleukin-1 $\beta$ plus tumor necrosis factor- $\alpha$. J. Med. Virol. 47:355363.

4. He, J., Y. Chen, M. Farzan, H. Choe, A. Ohagen, S. Gartner, J. Busciglio, X. Yang, W. Hofmann, W. Newman, et al. 1997. CCR3 and CCR5 are co-receptors for HIV-1 infection of microglia. Nature. 385:645-649.

5. Fauci, A.S., G. Pantaleo, S. Stanley, and D. Weissman. 1996. Immunopathogenic mechanisms of HIV infection. Ann. Intern. Med. 124:654-663.

6. D'Agati, V., and G.B. Appel. 1997. HIV infection and the kidney. J. Am. Soc. Nephrol. 8:138-152.

7. Rao, T.K.S. 1991. Human immunodeficiency virus (HIV) associated nephropathy. Annu. Rev. Med. 42:391-401.

8. Kimmel, P.L., A. Ferreira-Centeno, T. Farkas-Szaliasi, A.A. Abraham, and C.T. Garrett. 1993. Viral DNA in microdissected renal biopsies of HIV infected patients with nephrotic syndrome. Kidney Int. 43:1347-1352.

9. di Belgiojoso, G.B., A. Genderini, L. Vago, C. Parravicini, S. Bertoli, and N. Landriani. 1990. Absence of HIV antigens in renal tissue from patients with HIV-associated nephropathy. Nephrol. Dial. Transplant. 5:489-492.

10. Alpers, C.E., J. McClure, and S.L. Bursten. 1992. Human mesangial cells are resistant to productive infection by multiple strains of human immunodeficiency virus types 1 and 2. Am. J. Kidney Dis. 2:126-130.

11. Green, D.F., L. Resnick, and J.J. Bourgoignie. 1992. HIV infects glomerular endothelial cells and mesangial but not epithelial cells in vitro. Kidney Int. 41:956-960.

12. Nadasdy, T., O. Hanson-Painton, L.D. Davis, K.W. Miller, L.E. Debault, D.K. Burns, and F.G. Silva. 1992. Conditions affecting the immunohistochemical detection of HIV in fixed and embedded renal and non renal tissues. Mod. Pathol. 5:283-291.
13. Rappaport, J., J.B. Kopp, and P.E. Klotman. 1994. Host virus interactions and the molecular regulation of HIV-1: role in the pathogenesis of HIVassociated nephropathy. Kidney Int. 46:16-27.

14. Ray, P.E., X.H. Liu, D. Henry, L. Dye III, L. Xu, J.M Orenstein, and T.E. Schuztbank. 1998. Infection of human primary renal epithelial cells with HIV-1 from children with HIV-associated nephropathy. Kidney Int. 53:12171229.

15. Bódi, I., A. Andrew, and P.L. Kimmel. 1995. Apoptosis in human immunodeficiency virus-associated nephropathy. Am. J. Kidney Dis. 26:286-291.

16. Bruggeman, L.A., S. Dikman, C. Meng, S.E. Quaggin, T.M. Coffman, and P.E. Klotman. 1997. Nephropathy in human immunodeficiency virus-1 transgenic mice is due to renal transgene expression. J. Clin. Invest. 100:84-92.

17. Ameisen, J.C., J. Estaquier, T. Idziorek, and F. De Bels. 1995. Programmed cell death and AIDS pathogenesis: significance and potential mechanisms. Curr. Top. Microbiol. Immunol. 200:195-211.

18. Finkel, T.H., G. Tudor-Williams, N.K. Banda, M.F. Cotton, T. Curiel, C. Monks, T.W. Baba, R.M. Ruprecht, and A. Kupfer. 1995. Apoptosis occurs predominantly in bystander cells and not in productively infected cells of HIV-and SIV-infected lymph nodes. Nat. Med. 1:129-134.

19. Katsikis, P.D., E.S. Wunderlich, C.A. Smith, L.A. Herzenberg, and L.A. Herzenberg. 1995. Fas antigen stimulation induces marked apoptosis of T lymphocytes in human immunodeficiency virus-infected individuals. J. Exp. Med. 181:2029-2036.

20. Gehri, R., S. Hahn, M. Rothen, M. Steuerwald, R. Neusch, and P. Erb. 1996. The Fas receptor in HIV infection: expression on peripheral blood lymphocytes and role in the depletion of T cells. AIDS. 10:9-16.

21. Kaplan, D., and S. Sieg. 1998. Role of the Fas/Fas ligand apoptotic pathway in human immunodeficiency virus type 1 disease. J. Virol. 72:6279-6282.

22. Endres, M.J., P.R. Clapham, M. Marsh, M. Ahuja, J.D. Turner, A. McKnight, J.F. Thomas, B. Stoebenau-Haggerty, S. Choe, P.J. Vance, et al. 1996 CD4-independent infection by HIV-2 is mediated by fusin. Cell. 87:745-746.

23. Conaldi, P.G., L. Biancone, A. Bottelli, A. De Martino, G. Camussi, and A. Toniolo. 1997. Distinct pathogenic effects of group B coxsackieviruses on human glomerular and tubular kidney cells. J. Virol. 71:9180-9187.

24. Stricker, G.E, and L.I. Stricker. 1985. Glomerular cell culture. Lab. Invest. 53:122-131.

25. Racusen, L.C., C. Monteil, A. Sgrignoli, M. Lucskay, S. Marouillat, J.G.S. Rhim, and J.P. Morin. 1997. Cell lines with extended in vitro growth potential from human renal proximal tubule: characterization, response to inducers, and comparison with established cell lines. J. Lab. Clin. Med. 129:318-329.

26. Toniolo, A., C. Serra, P.G. Conaldi, F. Basolo, V. Falcone, and A. Dolei. 1995. Productive HIV-1 infection of normal human mammary epithelial cells. AIDS. 9:859-866.

27. Federsppiel, B., I.G. Melhado, A.M. Duncan, A. Delaney, K. Schappert, I. Clark-Lewis, and F.R. Jirik. 1993. Molecular cloning of the cDNA and chromosomal localization of the gene for a putative seven-transmembrane segment (7-TMS) receptor isolated from human spleen. Genomics. 16:707-712.

28. Shiraki, K., N. Tsuji, T. Shioda, K.J. Isselbacher, and H. Takahashi. 1997. Expression of Fas ligand in liver metastases of human colonic adenocarcinomas. Proc. Natl. Acad. Sci. USA. 94:6420-6425.

29. Kayagaki, N., A. Kawasaki, T. Ebata, H. Ohmoto, S. Ikeda, S. Inoue, K. Yoshino, K. Okumura, and H. Yagita. 1995. Metalloproteinase-mediated release of human Fas ligand. J. Exp. Med. 182:1777-1783.

30. Accornero, P., M. Radrizzani, D. Delia, F. Gerosa, R. Kurrle, and M.P. Colombo. 1997. Differential susceptibility to HIV-gp120-sensitized apoptosis in $\mathrm{CD}^{+} \mathrm{T}$-cell clones with different $\mathrm{T}$ helper phenotypes: role of CD95/CD95L interactions. Blood. 89:558-569.

31. McGahon, A.J., S.J. Martin, R.P. Bissonnette, A. Mahboubi, Y. Shi, R.J. Mogil, W.K. Nishioka, and D.R. Green. 1995. The end of the (cell) line: methods for the study of apoptosis in vitro. Methods Cell Biol. 46:153-185.

32. Clement, M.V., and I. Stamenkovic. 1994. Fas and tumor necrosis factor receptor-mediated cell death: similarities and distinctions. J. Exp. Med. 180: 557-567.

33. Biancone, L., A. De Martino, V. Orlandi, P.G. Conaldi, A. Toniolo, and G. Camussi. 1997. Development of inflammatory angiogenesis by local stimulation of Fas in vivo. J. Exp. Med. 186:147-152.

34. Bleul, C.C., M. Farzan, H. Choe, C. Parolin, I. Clark-Lewis, J. Sodroski, and T.A. Springer. 1996. The lymphocyte chemoattractant SDF-1 is a ligand for LESTR/fusin and blocks HIV-1 entry. Nature. 382:829-833.

35. Feng, Y., C.C. Broder, P.E. Kennedy, and E.A. Berger. 1996. HIV-1 entry cofactor: functional cDNA cloning of seven-transmembrane, $\mathrm{G}$ protein-coupled receptor. Science. 272:872-877.

36. Salvesen, G.S., and V.M. Dixit. 1997. Caspases: intracellular signaling by proteolysis. Cell. 91:443-446.

37. Nicholson, D.W., A. Ali, N.A. Thornberry, J.P. Vaillancourt, C.K. Ding, M. Gallant, Y. Gareau, P.R. Griffin, M. Labelle, Y.A. Lazebnik, et al. 1995. Identification and inhibition of the ICE/CED 3 protease necessary for mammalian apoptosis. Nature. 376:37-43.

38. Li, C.J., D.J. Friedman, C. Wang, V. Metelev, and A.B. Pardee. 1995. Induction of apoptosis in uninfected lymphocytes by HIV-1 Tat protein. Science. 268:429-431.

39. Westendorp, M.O., R. Frank, C. Ochsenbauer, K. Stricker, J. Dhein, H. 
Walczak, K.M. Debatin, and P.H. Krammer. 1995. Sensitization of T cells to CD95-mediated apoptosis by HIV-1 Tat and gp120. Nature. 375:497-500.

40. Smith, C.A., T. Farrah, and R.G. Goodwin. 1994. The TNF receptor superfamily of cellular and viral proteins: activation, costimulation, and cell death. Cell. 76:959-962.

41. Itoh, N., S. Yonehara, A. Ishll, M. Yonehara, S. Mizushima, M. Sameshima, A. Hasa, Y. Seto, and S. Nagata. 1991. The polypeptide encoded by the cDNA for human cell surface antigen Fas can mediate apoptosis. Cell. 66: 233-243.

42. Boonstra, J.G., F.J. van der Woude, P.C. Wever, J.C. Laterveer, M.R. Daha, and C. van Kooten. 1997. Expression and function of Fas (CD95) on renal tubular epithelial cells. J. Am. Soc. Nephrol. 8:1517-1524.

43. Nagata, S. 1997. Apoptosis by death factor. Cell. 88:355-365.

44. Nicholson, D.W. 1996. ICE/CED-3-like proteases as therapeutic targets for the control of inappropriate apoptosis. Nat. Biotech. 14:297-301.

45. Enari, M., H. Hug, and S. Nagata. 1995. Involvement of an ICE-like protease in Fas-mediated apoptosis. Nature. 375:78-81.

46. Kermer, P., N. Klocker, M. Labes, and M. Bahr. 1998. Inhibition of CPP32-like proteases rescues axotomized retinal ganglion cells from secondary cell death in vivo. J. Neurosci. 18:4656-4662.

47. Winston, J.A., and P.E. Klotman. 1996. Are we missing an epidemic of HIV-associated nephropathy? J. Am. Soc. Nephrol. 7:1-7.

48. Cohen, A.H., N.C.J. Sun, P. Shapshak, and D.T. Imagawa. 1989. Demonstration of human immunodeficiency virus in renal epithelium in HIV-associated nephropathy. Mod. Pathol. 2:125-128.

49. Hwang, S.S., T.J. Boyle, H.K. Lyerly, and B.R. Cullen. 1991. Identification of the envelope V3 loop as the primary determinant of cell tropism in HIV-1. Science. 253:71-74.

50. D'Souza, D., and V.A. Harden. 1996. Chemokines and HIV-1 second receptors. Nat. Med. 2:1293-1300.

51. Alkhatib, G., C. Combadiere, C.C. Broder, Y. Feng, P.E. Kennedy, P.M. Murphy, and E.A. Berger. 1996. CC CKR5: A RANTES, MIP-1 alpha, and MIP-1 beta receptor as a fusion cofactor for macrophage-tropic HIV-1. Science. 272:1955-1958.

52. Choe, H., M. Farzan, Y. Sun, N. Sullivan, B. Rollins, P.D. Ponath, L. Wu, C.R. Mackay, G. LaRosa, W. Newman, et al. 1996. The beta-chemokine receptors CCR3 and CCR5 facilitate infection by primary HIV-1 isolates. Cell. 85:1145-1148

53. Everall, I.P., P.J. Luthert, and P.L. Lantos. 1991. Neuronal loss in the frontal cortex in HIV-infection. Lancet. 337:1119-1121.
54. Laurence, J., D. Mitra, M. Steiner, L. Staiano-Coico, and E. Jaffe. 1996. Plasma from patients with idiopathic and human immunodeficiency virus-associated thrombotic thrombocytopenic purpura induces apoptosis in microvascular endothelial cells. Blood. 87:3245-3254.

55. Shi, B., U. De Gerolami, J. He, S. Wang, A. Lorenzo, J. Busciglio, and D. Gabuzda. 1996. Apoptosis induced by HIV-1 infection of the central nervous system. J. Clin. Invest. 98:1979-1990.

56. Savill, J. 1994. Apoptosis and the kidney. J. Am. Soc. Nephrol. 5:12-21.

57. Silvestris, F., S. Nagata, P. Cafforio, N. Silvestris, and F. Dammacco. 1996. Cross-linking of Fas by antibodies to a peculiar domain of gp120 V3 loop can enhance T cell apoptosis in HIV-1 infected patients. J. Exp. Med. 184:22872300 .

58. Stricker, K., E. Knipping, T. Böhler, A. Benner, P.H. Krammer, and K.-M. Debatin. 1998. Anti-CD95 (APO-1/Fas) autoantibodies and T cell depletion in human immunodeficiency virus type 1 (HIV-1)-infected children. Cell Death Different. 5:222-230.

59. Boldin, M.P., I.L. Mett, E.E. Varfolomeev, I. Chumakov, Y. ShemerAvni, J.H. Camonis, and D. Wallach. 1995. Self-association of the "death domains" of the p55 tumor necrosis factor (TNF) receptor and Fas/APO1 prompts signaling for TNF and Fas/APO1 effects. J. Biol. Chem. 270:387-391.

60. Tepper, C.G., S. Jayadev, B. Liu, A. Bielawska, R. Wolff, S. Yonehara, Y.A. Hannun, and M.F. Seldin. 1995. Role for ceramide as an endogenous mediator of Fas-induced cytotoxicity. Proc. Natl. Acad. Sci. USA. 92:8443-8447.

61. Yoshimura, S., Y. Banno, S. Nakashima, K. Takenaka, H. Sakai, Y. Nishimura, N. Sakai, S. Shimizu, Y. Eguchi, Y. Tsujimoto, and Y. Nozawa. 1998. Ceramide formation leads to caspase-3 activation during hypoxic PC12 cell death. Inhibitory effects of Bcl-2 on ceramide formation and caspase-3 activation. J. Biol. Chem. 273:6921-6927.

62. Sloand, E.M., J.P. Maciejewski, T. Sato, J. Bruny, P. Kumar, S. Kim, F.F. Weichold, and N.S. Young. 1998. The role of interleukin-converting enzyme in Fas-mediated apoptosis in HIV-1 infection. J. Clin. Invest. 101:195-201.

63. Lu, W., R. Salerno-Goncalvez, J. Yuan, D. Sylvie, D.S. Han, and J.M. Andrieu. 1995. Glucocorticoids rescue $\mathrm{CD}^{+}{ }^{+} \mathrm{T}$ cells from activation-induced apoptosis triggered by HIV-1: implications for pathogenesis and therapy. AIDS. 9:35-42.

64. Chinnaiyan, A.M., C. Woffendin, V.M. Dixit, and G.J. Nabel. 1967. The inhibition of pro-apoptotic ICE-like proteases enhances HIV replication. Nat. Med. 3:333-337.

65. Thompson, C.B. 1995. Apoptosis in the pathogenesis and treatment of disease. Science. 267:1456-1462. 